\title{
Hospital pharmacists' participation in audit in the United Kingdom
}

\author{
Siobhan Cotter, Martin McKee, Nicholas Barber
}

\begin{abstract}
Objective-To investigate systematically participation in audit of NHS hospital pharmacists in the United Kingdom.

Design-Questionnaire census survey. Setting-All NHS hospital pharmacies in the UK providing clinical pharmacy services.

Subjects-462 hospital pharmacies.

Main measures-Extent and nature of participation in medical, clinical, and pharmacy audits according to hospital management and teaching status, educational level and specialisation of pharmacists, and perceived availability of resources.
\end{abstract}

Results-416 questionnaires were returned (response rate 90\%). Pharmacists contributed to medical audit in $50 \%$ (204/410) of hospitals, pharmacy audit in $27 \%(108 / 404)$, and clinical audit in only $7 \%$ (29/404). Many pharmacies (59\% (235/399)) were involved in one or more types of audit but few $(4 \%,(15 / 399))$ in all three. Participation increased in medical and pharmacy audits with trust status (medical audit: 57\% (65/115) trust hospital $v 47 \%$ (132/281) non-trust hospital; pharmacy audit: $34 \%$ (39/114) $v \quad 24 \%$ (65/276)) and teaching status (medical audit: $58 \%(60 / 104)$ teaching hospital $v$ $47 \%(130 / 279)$ non-teaching hospital; pharmacy audit $30 \%$ (31/104) $v \quad 25 \%$ (68/273)) and similarly for highly qualified pharmacists (MPhil or PhD, MSc, diplomas) (medical audit: 54\% (163/302) with these qualifications $v 38 \%(39 / 103)$ without; pharmacy audit: $32 \%(95 / 298) v$ $13 \%(13 / 102))$ and specialist pharmacists (medical audit: 61\% (112/184) specialist $v$ $41 \%(90 / 221)$ non-specialist; pharmacy audit: $37 \%(67 / 182)$ v $19 \%$ (41/218)). Pharmacies contributing to medical audit commonly provided financial information on drug use (86\% 169/197). Pharmacy audits often concentrated on audit of clinical pharmacy services.

Conclusion-Pharmacists are beginning to participate in the critical evaluation of health care, mainly in medical audit.

(Quality in Health Care 1993;2:228-231)

\section{Introduction}

Since the 1989 NHS review ${ }^{1}$ medical audit, with doctors assessing the quality of their own work, has been the major focus of attention and funding in the United Kingdom (UK). ${ }^{2}$
This is changing: there is a growing emphasis on audit carried out by other professional groups, either alone or with others. Pharmacists have much to contribute to the audit process, not least because they frequently maintain records of their contributions to good prescribing practices. ${ }^{3}$ Also involving experts on medicines in audit of a health care process that includes the use of drugs has obvious benefits, such as help in improving prescribing and drug administration processes.

A few papers have reported the experiences of pharmacists auditing their own activities ${ }^{4}$ or participating with others in audit, ${ }^{6-10}$ but one study suggests that the extent to which this is happening is limited. ${ }^{9}$ Until now the extent to which pharmacists throughout the UK are involved in audit has not been systematically investigated. We report the results of a study that examined the nature and extent of hospital pharmacists' participation in medical, pharmacy, and clinical audit activities within the NHS. This information identifies examples of current audit activities, explores the determinants of involvement in audit, provides a baseline against which future initiatives can be evaluated, and suggests areas where such initiatives might be directed.

\section{Methods}

In March 1992 a postal questionnaire was sent to all NHS hospital pharmacies that provided clinical pharmacy services (that is, pharmacies where a pharmacist was present during normal working hours and where services in addition to supplying drugs were provided). These pharmacies had been identified by prior communication with district pharmaceutical officers in England, chief administrative pharmaceutical officers in Scotland and Wales, directors of pharmaceutical services in Northern Ireland, and chief pharmacists in special health authorities. The questionnaire had previously been tested among a panel of clinical pharmacists from throughout England and Wales. It inquired about all aspects of hospital clinical pharmacy services and included a section on pharmacists' participation in audit; their contribution to medical audit, and their involvement in clinical audit (question phrased to exclude contribution to medical audit) and pharmacy audit. The box shows the definitions of these terms, as used in the questionnaire. Each question had a precoded section asking if pharmacy staff routinely participated in the audit activity and 


\begin{tabular}{|c|c|}
\hline \multicolumn{2}{|c|}{ Definitions of audit } \\
\hline Medical audit & $\begin{array}{l}\text { - audit of the practices of } \\
\text { doctors }\end{array}$ \\
\hline Clinical audit & $\begin{array}{l}\text { - audit of the practices of } \\
\text { health care professionals }\end{array}$ \\
\hline Pharmacy audit & $\begin{array}{l}\text { - audit of the practices of } \\
\text { pharmacists }\end{array}$ \\
\hline
\end{tabular}

an open section inviting respondents to specify these activities. The question on medical audit additionally requested information on the extent of provision of different types of help and information for the audit process. Postal reminders were sent after six weeks, and further non-responders were followed up by telephone.

Data were analysed with the statistical package for the social sciences (SPSS/PC+). Information from ordinal categorical variables was collapsed to form binary data (none and very little $=$ not provided; a moderate amount and lots (on average two hours a week or more $)=$ provided) and described using frequencies. Comments volunteered by respondents to open sections of questions were coded with key words.

A priori hypotheses, on relations between participation in audit (dependent variables) and demographic, staffing, and other (independent variables), were tested. Among the independent variables tested were pharmacists' perceptions of increased availability of resources for clinical pharmacy services owing to a Department of Health policy document, $\mathrm{HC}(88) 54^{11}$ and the Nuffield report, ${ }^{12}$ both of which recommended the development of clinical pharmacy in the hospital sector in the UK. Although the documents pre-date audit, they may have increased pharmacists' involvement in wider aspects of health care, including audit. The data set was a census because of total coverage of UK NHS hospital

Table 1 Percentage ${ }^{*}$ (number) of pharmacies participating in audit in NHS hospitals in the UK, according to hospital managment and teaching status

\begin{tabular}{lcccccc}
\hline $\begin{array}{l}\text { Type of audit } \\
\text { activity }\end{array}$ & Management status & & Teaching status $\neq$ & \\
\cline { 2 - 3 } & NHS trust & Directly managed unit & & Non-teaching & Teaching \\
\hline Medical audit & $57(65 / 115)$ & $47(132 / 281)$ & & $47(130 / 279)$ & $58(60 / 104)$ \\
Pharmacy audit & $34(39 / 114)$ & $24(65 / 276)$ & & $25(68 / 273)$ & $30(31 / 104)$ \\
Clinical audit & $11(13 / 115)$ & $5(15 / 275)$ & & $5(13 / 275)$ & $13(13 / 102)$ \\
\hline
\end{tabular}

^Percentages vary slightly from overall results owing to missing data

†Pharmacies in which a pharmacist was present during normal working hours and services in addition to supplying drugs were provided.

tLocation in medical school teaching hospitals.

Table 2 Percentage* (number) of pharmacies participating in audit in NHS hospitals $†$ in the UK, according to educational level and specialisation of pharmacists

\begin{tabular}{lccccc}
\hline $\begin{array}{l}\text { Type of audit } \\
\text { activity }\end{array}$ & \multicolumn{2}{l}{$\begin{array}{l}\text { Employment of pharmacists with higher } \\
\text { qualifications } \ddagger\end{array}$} & & \multicolumn{2}{l}{$\begin{array}{l}\text { Employment of specialist clinical } \\
\text { pharmacists } \$\end{array}$} \\
\cline { 2 - 3 } \cline { 7 - 7 } & Not employed & Employed & & Not employed & Employed \\
\hline Medical audit & $38(39 / 103)$ & $54(163 / 302)$ & & $41(90 / 221)$ & $61(112 / 184)$ \\
Pharmacy audit & $13(13 / 102)$ & $32(95 / 298)$ & & $19(41 / 218)$ & $37(67 / 182)$ \\
Clinical audit & $3(3 / 103)$ & $9(26 / 297)$ & & $4(9 / 217)$ & $11(20 / 183)$ \\
\hline
\end{tabular}

$\star$ Percentages vary slightly owing to missing data.

tPharmacies in which a pharmacist was present during normal working hours and services in †Pharmacies in which a pharmacist was prese

addition to supplying drugs were provic
$\ddagger$ MPhil or $\mathrm{PhD}, \mathrm{MSc}$, or diplomas.

$\ddagger M P h i l$
jSpending $50 \%$ or more of their time working in a specialist area of pharmacy - for example, an oncology specialist pharmacist. pharmacies and a high response rate (see results below). This made most statistical tests inappropriate. To assess the effects of staffing on participation in audit activities, however, the data were treated as a sample in time and $\chi^{2}$ tests for trend were conducted.

\section{Results}

GENERAL RESULTS

The response rate to the questionnaire was $90 \%$ (416/462). Within the UK the response rates varied from $61 \%(14 / 23)$ in Northern Ireland to $96 \%(23 / 24)$ in Wales. Except for Scotland, where all non-responders were nonteaching hospital pharmacies, and Northern Ireland, where $67 \%$ (six) were non-teaching hospital pharmacies, similar proportions of responding and non-responding pharmacies were located in teaching hospitals $(27 \%, 112$ and $23 \%, 11$ respectively).

Pharmacists reported contributing to medical in $50 \%(204 / 410)$ of hospitals, undertaking pharmacy audit in $27 \%$ (108/404) and participating in clinical audit in only $7 \%$ (29/404). Many pharmacies (59\%, 235/399) were involved in one or more types of audit but few $(4 \%, 15 / 399)$ in all three types.

EFFECT OF HOSPITAL TYPE

Although half of all pharmacies surveyed reported participation in the medical audit process, a higher proportion of those in NHS trust hospitals and medical school teaching hospitals contributed than those in directly managed units or non-teaching hospitals (table 1). The same observation applied to pharmacies' participation in pharmacy audit; small numbers precluded comments on variations in participation in clinical audit.

\section{EFFECT OF STAFFING FACTORS}

The likelihood of pharmacists' participation in medical and pharmacy audit increased significantly with increasing numbers of pharmacy staff $\left(\chi^{2}=20 \cdot 8\right.$ and $25 \cdot 2$ respectively, $p<0.001)$. The odds ratio for conduct of pharmacy audit increased twofold when four to six pharmacists were employed and fourfold when more than 10 were employed; the corresponding odds ratios for contribution to medical audit were 1.7 and $3 \cdot 1$ respectively.

The presence of pharmacists with higher qualifications (MPhil or $\mathrm{PhD}, \mathrm{MSc}$, or diplomas) or specialist clinical pharmacists (who spend half of their time or more in a clinical pharmacy specialty) was associated with pharmacists' participation in all types of audit (table 2). When pharmacists with higher degrees were employed the proportion of pharmacies conducting pharmacy audit more than doubled, and when specialist clinical pharmacists were present the proportion of pharmacies contributing to medical audit increased by $20 \%$, from $41 \%$ (90 pharmacies) to $61 \%(112)$.

EFFECT OF PERCEIVED RESOURCE SHIFTS Some respondents indicated that the health circular $\mathrm{HC}(88) 54^{11}$ and the Nuffield report ${ }^{12}$ had increased resources for hospital clinical 
Table 3 Percentage (number) of pharmacies participating in audit in NHS hospitals $\dagger$ in the UK, according to pharmacist's perceptions of increased availability of resources for clinical pharmacy owing to HC(88) 54 and Nuffield report

\begin{tabular}{lcccccc}
\hline \multirow{2}{*}{$\begin{array}{l}\text { Type of audit } \\
\text { activity }\end{array}$} & $H C(88) 54$ & & \multicolumn{2}{l}{ Nuffield report } \\
\cline { 2 - 3 } \cline { 6 - 7 } & No change & Increased activity & & No change & Increased activity \\
\hline Medical audit & $44(100 / 227)$ & $59(101 / 172)$ & & $47(142 / 303)$ & $63(47 / 75)$ \\
Pharmacy audit & $19(43 / 224)$ & $38(64 / 170)$ & & $24(72 / 300)$ & $38(28 / 75)$ \\
Clinical audit & $7(16 / 222)$ & $8(13 / 171)$ & & $7(20 / 299)$ & $8(6 / 75)$ \\
\hline
\end{tabular}

$\star$ Percentages vary slightly owing to missing data.

tPharmacies in which a pharmacist was present during normal working hours and services in addition to supplying drugs were provided.

Table 4 Nature of the contribution of hospital pharmacies to medical audit in NHS hospitals * in the UK

\begin{tabular}{lc}
\hline Contribution $\dagger$ & Percentage (No) pharmacies \\
\hline Financial information on drug use & $86(169 / 197)$ \\
Help in creation of prescribing policies & $71(134 / 188)$ \\
Information on adherence to agreed prescribing policies & $62(115 / 186)$ \\
Information on problems in prescribing process & $48(86 / 180)$ \\
\hline
\end{tabular}

$\star$ Percentages vary slightly owing to missing data.

†Number of respondents to individual questions varied slightly

pharmacy services. An association was observed between preceived increases in resources, consequent on these reports, and participation in medical and pharmacy audit (table 3). Pharmacies in which resources were considered to have increased as a result of the health circular were more commonly participating in medical audit $(59 \%, 101 / 172)$ and pharmacy audit $(38 \%, 64 / 170)$ than those in which resources were considered to have been unaffected $(44 \%, 100 / 227$ and 19\%, 43/224 respectively). Similarly, pharmacies were more commonly participating in medical audit $(63 \%, 47 / 75)$ and pharmacy audit $(38 \%$, $28 / 75$ ) in hospitals in which it was thought that clinical pharmacy resources had increased as a result of the Nuffield report than in those where no effect had been perceived $(47 \%$, $142 / 303$ and $24 \%, 72 / 300$ respectively).

SPECIFIC CONTRIBUTIONS TO AUDIT

Of pharmacists' contributions to medical audit, the commonest was providing financial information on drug use $(86 \%, 169 / 197)$ (table 4). Many pharmacies helped to create prescribing policies $(71 \%, 134 / 188)$ and fed information on adherence to such policies back to the audit group $(62 \%, 115 / 186)$. A smaller proportion $(48 \%, 86 / 180)$ supplied information on problems experienced by pharmacists with the process of doctor's prescribing. Some pharmacies volunteered additional information on contributions to medical audit. Of these, 36 stated that they were involved in directly auditing prescribing. Examples given included audit of the prescribing of antibiotics, anti-emetics, and depot neuroleptics.

Those pharmacists who specified the pharmacy audits carried out indicated that activities pursued included the audit of interventions (54 pharmacies), when pharmacists make inquiries (often of a doctor) to satisfy themselves that a prescription is appropriate, often resulting in alteration of the prescription, and audit of specific clinical pharmacy services such as therapeutic drug monitoring, central intravenous additives services, and drug information services (40 pharmacies), errors in pharmacy processes such as dispensing (16), and service response time (16).

The clinical audit activities pursued varied from multidisciplinary audit of whole departments (25) and of medicine usage (17) to auditing other hospitals or their departments (three). Specific examples included audit of physiotherapy and dietetics departments, audit of laxative and antacid use, and audit of drug supply and distribution at other hospitals.

\section{Discussion}

The results of this census survey suggest that pharmacists are beginning to become involved in audit activities, particularly in medical audit. They are starting to evaluate their own activities and services but have rarely, as yet, become involved with other health care professionals in clinical audit. This picture is true for most parts of the UK.

EXPLANATIONS FOR PRESENT LEVEL OF PARTICIPATION IN AUDIT

Pharmacists' involvement in medical audit tended to be based on providing information. This is a traditional and, perhaps, more easily assumed role for pharmacists than that of direct involvement in the prescribing arena and in creating prescribing policies. Pharmacists were less involved in using medical audit as a means of alerting doctors to prescribing problems; fewer than a quarter of pharmacies surveyed did this. Prescribing problems are usually addressed in one to one doctor-pharmacist discussion in the ward or through hospitalwide policies, often linked to formulary management. Yet prescribing problems are common, and research has shown that pharmacy has a unique insight into individual problems in particular medical specialties through its system of ward pharmacy $^{13}$ and because of its use of computerised records of drug usage. Medical audit enables systematic review of prescribing problems and the development of strategies for their future avoidance, all as part of an educational process.

The most common pharmacy audit activities were audit of the ward pharmacy service, of prescription monitoring, and of more specialised services such as therapeutic drug monitoring. The existence of these programmes is encouraging and signifies a desire among some pharmacists to evaluate critically their clinical services. These internal, professional audits also complement external audits currently performed on some sections of pharmacy departments, such as manufacturing units.

The virtual absence of pharmacists' activity in clinical audit may not indicate their lack of interest. Rather, it may simply reflect the limited extent to which clinical audit was performed in NHS hospitals at the time of the survey. The nature of the audits in which 
pharmacy was involved may signify, to some extent, the expansion of the pharmacy manager's responsibilities to encompass managerial responsibility for paramedical groups within hospitals.

Pharmacies in teaching hospitals participated more frequently in all audit activities. From evidence gathered in this survey the most likely reason is their greater development of clinical pharmacy services with more highly qualified pharmacists. The same pattern of greater participation was seen in trust hospitals and in hospitals that employed pharmacists with higher degrees and specialist clinical pharmacists; it is not immediately obvious why this should be so. The association between perceived increases in resources for clinical pharmacy services and increased participation in audit may mean that pharmacy managers committed to developing clinical pharmacy used documents such as $\mathrm{HC}(88) 54^{11}$ and the Nuffield report ${ }^{12}$ to support their efforts. Since neither of these resulted in additional direct government funding the association may be a proxy for a high level of commitment by pharmacy managers and general managers to make services more appropriate.

\section{NEXT STEPS}

The variation in the extent to which pharmacists have become involved in audit demonstrates considerable scope for development. By providing examples of what is being done this survey suggests ways in which pharmacies not yet involved in audit might start.

Several factors could contribute to increasing pharmacists involvement in audit. Pharmacists have yet to optimise their contribution to medical audit, becoming team workers not simply providers of information. Doctors would welcome greater involvement by pharmacists in audit, ${ }^{14}$ and pharmacists may be raising artificial barriers that limit their participation. The difficulty of undertaking audit in hospital pharmacies with only one or two pharmacists may be overcome by organising programmes with nearby hospitals, possibly using pharmacists with higher degrees to lead the process. This model of audit may also be applicable to community pharmacy where, currently, pharmacists often practice alone. The new regional offices could provide useful leadership and coordination for such schemes. Although audit must be led locally, academic pharmacy practice units could accelerate its development by providing training and by disseminating information on audit methods. This would be an appropriate use of funds for clinical audit. The medical royal colleges have had a key role in promoting medical audit and disseminating guidance on good practice. Similar activity is needed in pharmacy. The Pharmaceutical Society should assume this initiative. Its recent appointment of an audit fellow, in association with the Department of Health, is but a first step; it is essential that the resulting work is not confined to pharmacy audit but seeks to integrate pharmacists into clinical audit.

Clinical audit has much to gain from greater participation by pharmacists. Hospital pharmacies routinely gather information on several aspects of the process of drug use that could be usefully incorporated into audit cycles. This should facilitate linking health care processes with outcomes and help to enhance both. Such a scenario will necessitate research into aspects of service provision, which audit should stimulate by providing the research questions. ${ }^{15}$ With increasing emphasis on multidisciplinary audit, these questions will be addressed by multidisciplinary health services research, to which pharmacists can contribute by promoting increased communication and collaboration between pharmacy and mainstream health services research centres.

This study was carried out as part of a $\mathrm{PhD}$ programme (SMC) and funded jointly by the Department of Health (as part of a Pharmacy Practice Research Enterprise Scheme Award) and the pharmaceutical division of North West Thames Regional Health Authority. We thank all those who took part in this survey for their time and effort.

1 Secretaries of State for Health, Wales, Northern Ireland, and Scotland. Working for Patients. London: HMSO, and Scotland.

2 NHS Management Executive. Audit of nursing, midwifery, health visiting, and therapy professions. Allocation of funds 1992/3. London: Department of Health, 1992. (EL92(23).)

3 Cotter S, McKee M, Barber N. Pharmacists and prescribing: an unrecorded influence (editorial). Quality in Health Care 1993;2:75-6.

4 Audit in pharmacy. Royal Pharmaceutical Society working party report (Chair: $\mathrm{Mr}$ NL Wood), Pharmaceutical party report (Chair:

5 Hynam B. Pharmaceutical audit in practice. Pharmaceutical Fournal 1993;250:844-5.

6 Ridley-Siegert D, van Kan E, Anthistle J. Audit of benzodiazepine prescriptions in hospital admissions. benzodiazepine prescriptions in hospital

7 Robb J, McEvoy J, Greenwood E, Hollands R, Kopelman $P$. Blood glucose monitoring: completing the audit cycle. Pharmaceutical fournal 1992;248:590-1.

8 Sandler DA, Heaton C, Garner ST, Mitchell JRA. Patients and general practitioners' satisfaction with information given on discharge from hospital: audit of a new information card. BMF 1989;299:1511-3

9 Eccles S, Barber N, Frater A, Wilson P. A better pill to swallow. Health Services fournal 1992;102:22-3.

10 Davies G, Lewis L. Clinical audit - a new development? Pharmaceutical fournal 1989;243(suppl):HS30-1.

11 Department of Health. Health services management. The way forward for hospital pharmaceutical services. London: HMSO, 1988. (HC (88)54.)

12 Pharmacy. The report of a committee of inquiry appointed by the Nuffield Foundation (Chair Sir K Clucas). London: Nuffield Foundation (Chair Sir K Clucas).

Nuffield Foundation 1986. (Nuffield Report.)
13 Batty R, Barber N. Ward pharmacy: a foundation for prescribing audit? Quality in Health Care 1992;1:5-9.

14 Harris S. The pharmacist's contribution to medical audit (MSc Thesis). London: University of London, 1991.

15 Proctor S. Why clinical research needs medical audit (editorial). Quality in Health Care 1993;2:1-2. 